\title{
DEFICIENCIA MENTAL E MALFORMAÇÕES EM CRIANÇA COM TRANSLOCAÇÕES CROMOSSOMICAS 5/13
}

\author{
Valeriana Moura Ribeiro* \\ IRIS FERRARI ** \\ LiLIA M. A. MOREIRA ***
}

Translocações cromossômicas equilibradas entre o cromossomo número 5 e outro qualquer, têm sido verificadas em progenitores de crianças com síndrome do "cri du chat" e malformações físicas múltiplas ${ }^{9}$. As manifestações fenotípicas decorrem da segregação cromossômica não equilibrada, proveniente do estado de duplicação e/ou deficiência de segmentos gênicos na progenie afe$\operatorname{tada}^{4,6,12}$.

Justificamos o registro deste caso pelo fato de não termos encontrado na literatura consultada, qualquer referência sobre a associação de atraso do desenvolvimento neuromotor, retardo mental e malformações múltiplas em translocações equilibradas $5 / 13$.

\section{OBSERVAÇAOO}

J.A.G. (Reg. HCRP - 22.278) sexo masculino, 9 anos de idade, vem sendo acompanhado desde a idade de 11 meses devido a retardo no desenvolvimento neuromotor. Antecedentes pessoais - Nascido a termo de parto domiciliar, com peso de $2000 \mathrm{gr}$. E óltimo de 8 filhos, nascido quando a mãe tinha 41 anos e o pai 46 . Durante o quinto mês de gestação, a mãe apresentou eritema difuso. Nasceu no domicílio, sem assistência médica, e com cianose. Apresentou dificuldade para sugar nos primeiros dias e deglutinação irregular. Teve surtos freqüentes de bronquite e dispnéia. Com 11 meses apresentou desnutrição de II grau; foram observados palato ogival, epicanto bilateral, alterações nos dedos das mãos, que se apresentavam curtos, com encurvamento do $2 .^{\circ}$ e $5 .^{\circ}$ dedos e com ausência da prega palmar transversa. Exame neurológico evolutivo - Sempre apresentou desenvolvimento neuro-psicomotor precário, respondendo de modo insuficiente aos estimulos sonoros e luminosos. Nos primeiros meses de vida apresentou súbitas crises de cianose, hipertonia axial, movimentos clônicos de duração rápida, sudorese intensa, dispnéia e incontinência de fezes. Até essa ocasiāo, o choro era fraco e fino, semelhante ao miado de gato. Aos 11 meses de idade o perímetro craniano era de $42 \mathrm{~cm}$, a musculatura hipotônica, não sentava e nem rolava, mostrava-se pouco ativo intelectualmente e indiferente ao meio ambiente, mesmo quando solicitado. Com a correcão alimentar, aos 15 meses de idade, o padrão

Departamento de Neuropsiqiuatria e Psicologia Médica (Prof. J. Armbrust-Figuelredo) e Departamento de Genética (Prof. I. Ferrari) da Faculdade de Medicina de Ribeirão Preto: *Professor Assistente; ** Professor Adjunto; *** Mestre em Genética. 
neuromotor correspondia a 10 meses. Iniciou deambulação com apoio aos 18 meses. Nessa mesma época, emitia sons sem significado. Com 3 anos ainda não falava, mas atendia algumas solicitaçoes. Em exames sucessivos, observou-se assimetria facial, em detrimento da hemiface esquerda, e estrabismo convergente bilateral. Marcha e postura tendendo a hipotônica. Voltou à consulta aos 9 anos (peso 23 kg; estatura $1,26 \mathrm{~m}$ ), calmo, atento ao ambiente; dominância à direita de mão e pé. Provas de coordenação ao nivel de 6 anos. Produção pedagógica em nivel de 5 para 6 anos. Constatada surdês bilateral, passou a usar aparelho de audição. Comunica-se com satisfatória expressividade. Iniciou estudo dirigido para deficiente auditivo. Persiste o estrabismo convergente bilateral; tem controle dos esfincteres; banha-se sozinho, porém tem poucos cuidados pessoais. Estudo radiológico do crânio - Módulo e indice cefálico normaìs. Estudo radiológico das mãos - Encurtamento da $2^{*}$ falange do $2^{\circ}$ e $5^{\circ}$ dedos, bilateralmente. Estudo oftalmológico - Leve endotropia do olho direito. Estudo eletrencefalográfico - EEG n.o 8.668, realizado em 23/10/69, durante o sono barbitúrico, apresentou atividade de fundo normal e surtos de ondas agudas de elevado potencial, 150-180 uV, nas projeções C3-F7 e, secundariamente, nas demais áreas. Avaliacão da capacidade intelectual - Embora limitada pela surdês, revelou do ponto de vista visuo-motor, respostas corretas até o nível de 6 anos, segundo a Escala de Inteligência Stafford-Binet e Escala de Desenvolvimento de Gesell. Demonstrou ter

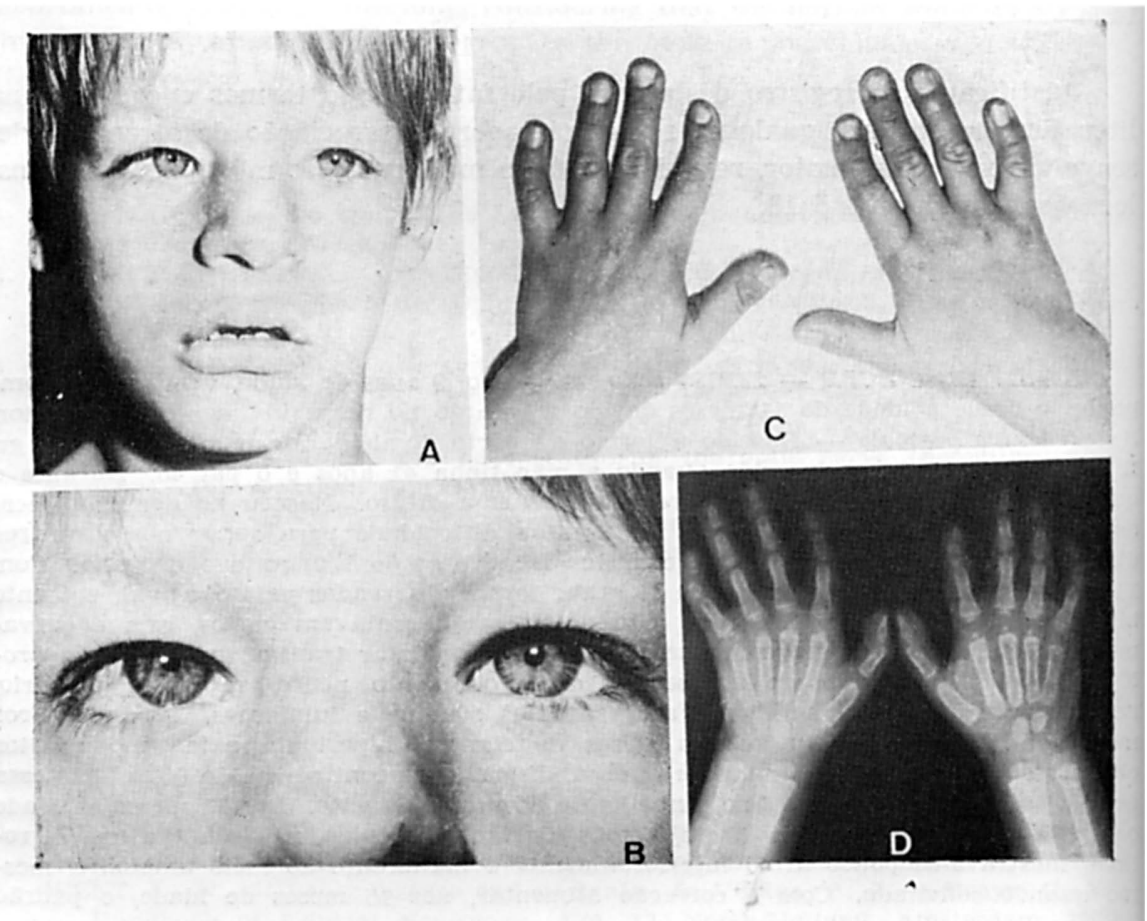

Fig. 1 - Caso J.A.G.: em A e B, aspecto da face mostrando epicanto bilateral e estrabismo convergente; em $C$, encurvamento do $2^{\circ} e 5^{\circ}$ dedos das mãos; em $D$, estudo radiológico, mostrando encurtamento da $2^{a}$ falange do $2^{\circ} 6$ 5. dedos bilateralmente. 
noção de igualdade, diferença, das partes do corpo, uso e função de objetos, e formas geométricas. Em memória e concentraçao, respondeu a provas até 4 anos e 6 meses. Exame otoneurológico - Disacusia neuro-sensorial bilateral grave; discriminação vocal ausente bilateralmente. Impedanciometria com reflexo stapediano ausente bilateralmente. Estudo cromossómico - Foram feitos em cultura de linfócitos pela técnica de Moorhead ${ }^{11}$, modificada por Ferrari ${ }^{5}$ e o bandeamento cromossômico pela técnica de Scheres ${ }^{15}$ para obtenção de bandas G. A análíse cromossómica do paciente, em coloração convencional, revelou 46 cromossomos; auséncia de um membro de grupo $D$; um elemento do grupo $G$ a mais e outro cromossa extra, anormal, de tamanho comparável ao número 2.

O carí́típo fol interpretado como $46, X Y,-B,-D,+t(B p D p),+t(B q D q)$ (fig. 2); a análịse do padrão de bandas, revelou tratar-se de translocacão reciproca aparentemente equilibrada entre os bracos longos e curtos dos cromossomos 5 e 13, estabelecendo-se o cariótipo 46, XY, (t5; 13) (p11; q11) (fig. 3).

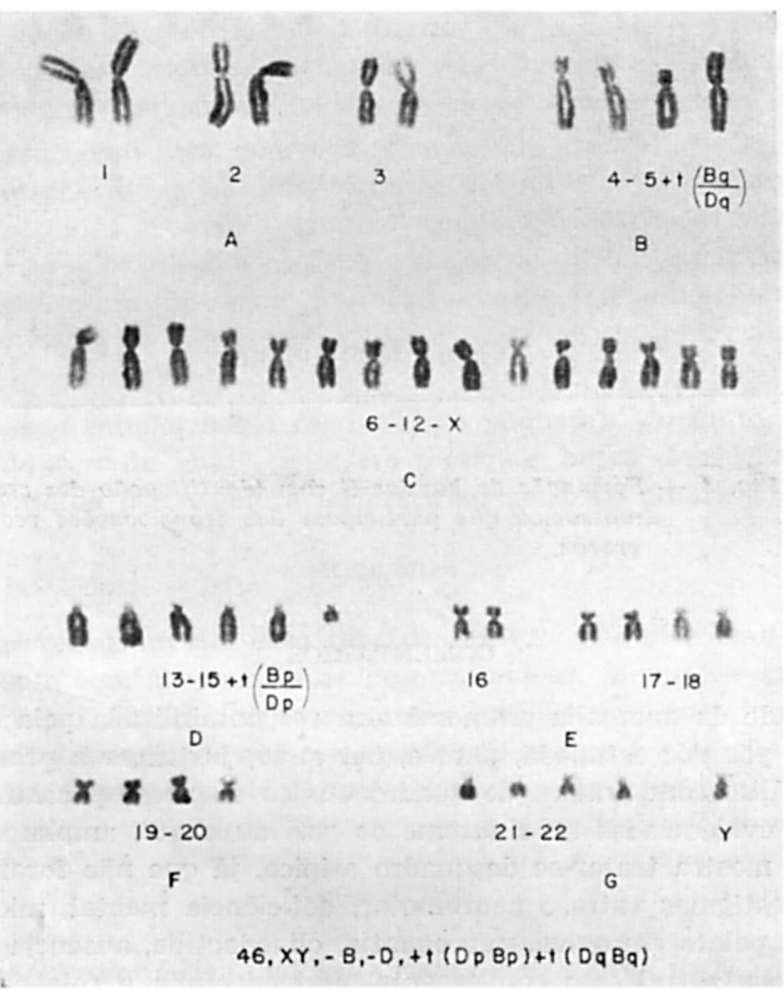

Fig. 2 - Cariótipo do paicente, com os cromossomos rearranjados colocalos nos grupos $B$ e $D$. 

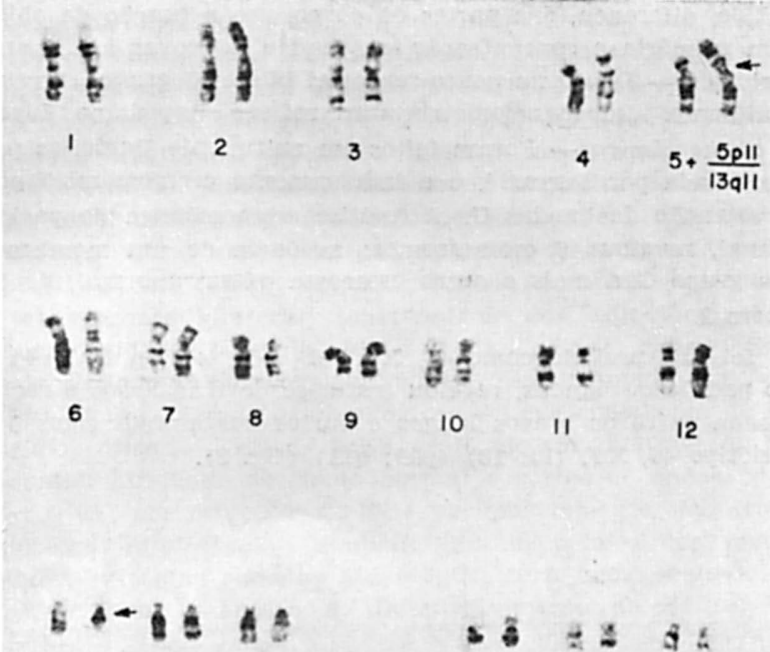

$13+\frac{13 q 11}{5 p 11} \quad 14 \quad 15$

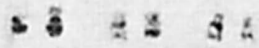

$\begin{array}{lll}16 & 17 \quad 18\end{array}$

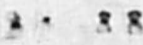

1920

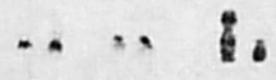

$21 \quad 22 \quad X Y$

$46, X Y,+(5 ; \mid 3)(p) \mid q \| 1)$

Fig. $\$$ - Formação de bandas $G$ com identificação dos cromossomos que participam das translocacōes reciprocas.

\section{COMENTARIOS}

A raridade da anomalia cromossômica responsabilizada pela determinação da sindrome por nós estudada, parece, por si só, justificar a presente comunicação A análise comparativa do quadro clínico do nosso paciente com as caracteristicas evidenciadas na sindrome de "cri du chat", amplamente revisada por Pinto ${ }^{13}$, mostra tratar-se de quadro atípico, já que não foram registrados todos os 11 estigmas (atraso neuromotor, deficiência mental, microcefalia, hipertelorismo, palato em ogiva, micrognatia, clinodactilia, ausência da linha palmar transversa, estrabismo convergente, arrinencefalia e colobomata com ou sem catarata) considerados típicos para o diagnóstico. Também as características dermatoglificas presentes na sindrome do "cri du chat", com prega palmar transversa, alta frequência de padrões tenares, trirrádio axial distal e deficiência de presilhas ulnares, não foram observados em nosso paciente; esse 
estudo mostrou-se normal. Assim, a confirmação da síndrome do "cri du chat" em nosso paciente, parece muito discutível.

(0) estudo cromossômico da sindrome do "cri du chat", no primeiro caso publicado ${ }^{7}$, revelou a deficiência no braço curto do cromossomo número 5 ; investigações ulteriores revelaram translocações, também do braço curto do cromossomo número 5 sobre o braço longo de cromossomo do grupo $\mathrm{D}$ (13-15) na mãe, tia e avô materno do paciente ${ }^{8}$. Há referências na literatura de casos da síndrome do "cri du chat" com translocação de partes de cromossomos ou de cromossomos quase inteiros sobre o número 5 , com perda do seu braço curto, sendo que os pais desses pacientes apresentavam cariótipo normal ${ }^{2}, 3,10,16$. No caso relatado por Borgaonkar e col. ${ }^{1}$, de duas translocações cromossômicas recíprocas $5 / 14$ de ocorrência familial e sem perda aparente de material cromossômico, os portadores do rearranjo eram normais. Reinwein e Wolf ${ }^{14}$ analisaram um paciente com 45 cromossomos e translocação $5 q / \mathrm{D} 2 q$, com severo retardo no desenvolvimento neuromotor, microcefalia, rosto fino, hipertelorismo, estrabismo convergente, encurtamento do $5^{\circ}$ dedo de ambas as mãos e $4^{\circ}$ dedo da mão esquerda associado a hipermotilidade; o estudo radiológico das mãos revelou que o $5^{\circ}$ metacarpiano direito e $4^{\circ}$ e $5^{\circ}$ esquerdos eram anormalmente curtos Alguns dos sintomas do nosso caso se assemelham aos deste paciente, sugerindo homologia de regiões cromossômicas atingidas no rearranjo.

Portanto, em nosso caso, podemos afirmar que a translocação apresentada é esporádica, originando-se na gametogênese de um dos progenitores, já que o cariótipo dos parentes estudados foram normais Nossa impressão é que possa ter ocorrido nas regiōes de quebra, nos eventos de quebra e rejunção, a perda de alguns genes para $5 \mathrm{p}$ e/ou mutação gênica, ou ainda efeito de posição com inativação de alguns genes, decorrendo daí as malformações físicas apresentadas pela criança.

Mediante esse estudo, nosso caso não se enquadra, portanto, tipicamente na síndrome do "cri du chat", nem em qualquer outra descrição de quadro clínico decorrente da perda gênica no braço ao longo do cromossomo 13.

\section{RESUMO}

Os autores registram um çaso raro de retardo mental e malformações físicas em paciente com anormalidades cromossômicas. A análise cromossômica đo paciente revelou cariótipo aparentemente equilibrado. Entretanto, são consideradas as possibilidades de que nos eventos de quebra e rejunção dos cromossomos, tenha ocorrido perda de alguns genes para 5p e/ou 13q; mutação gênica ou, ainda, efeito de posições dos segmentos cromossômicos rearranjados.

\section{SUMMARY}

\section{Mental retardation and malformation in a child with $5 / 13$ chromosome translocation}

An unusual case of mental retardation and physical malformations with chromosome abnormalities in a 9 year old boy is reported. Chromosomal analy- 
sis showed either breakage and delation from some gens to $5 p$ and/or $13 q$; genic mutation or, perhaps, efect of position in re-adjusted chromosomic segments.

\section{REFERENCIAS}

1. BORGAONKAR, D. S.; BLAIR, S. M.; LUTZ, J. B.; KELLY, T.; TICE, R. R.; DELANEY, N. V.; HUTCHINSON, J. R. \& BIAS, W. B. - Cytogenetic study of a 5/14 translocation in man. J. Hered. 64:299, 1973.

2. CAPOTORTI, L. \& FERRANTE, E. - Translocazione $D / R$ in un lattante con 45 cromosomi e con alcune manifestazioni fenotipiche alello malattia del "cri-du-chat". Acta Paediat. Latina 19:471, 1966.

3. CATTI, A. \& SCHMID, W. - A pericentric inversion $5 p-q+$, and additional complex rearrangement in a case of "cri-du-chat" syndrome. Cytogenetics 10:50. 1971.

4. DE CAPOA, A.; WARburton, R.; BREG, W. R.; MILleR, D. A. \& Miller, D. J. - Translocation heterozygosis: A cause of five cases of the "cri-du-chat" syndrome and two cases with a duplication of chromosome number five in three families. Amer. J. hum. Genet. 19:586, 1967.

5. FERRARI, I. - Estudo de alteracões cromossômicas em pacientes portadores de anormalidades físicas múltiplas e retardo mental. Tese de Doutoramento. Faculdade de Medicina de Ribeirão Preto, 1968.

6. JACKSON, L. \& BARR, M. - A 45, XY, -5,-15,+t(5q 15q) "cri-du-chat" child. J. med. Genet. 7:161, 1970.

7. LEJEUNE, J.; LAFOURCADE, J.; BERGER, R.; VIALATTE, J.; BOESWILLWALD, M.; SERINGE, P. \& TURPIN, R. - Trois cas de délétion partielle du bras court d'un chromosome 5. C. R. Acad. Sci. (Paris) 257:3098, 1963.

8. LEJEUNE, J.; LAFOURCADE, J.; BERGER, R. \& TURPIN, R. - Ségrégation familiale d'une translocation 5-13 determinant une monosomie et trisomie partielles du bras ocurt du chromosome 5: maladie du "cri-du-chat" et la "réciproque". C. R. Acad. Sci. (Paris) 258:5767, 1964.

9. LEJEUNE, J.; LAFOURCADE, J.; BeRGER, R. \& RETHORE, M. O. - Maladie du "cri-du-chat" et sa "réciproque". Ann. Génét. 8:11, 1965.

10. MENNICKEN, V.; PFEIFFER, R. A.; PUYN, U.; WORBES, H. \& WAGENER, A. - Klinische und cytogenetische befund von 7 patienten mit "cri-du-chat" syndrom. Z. Kinderheilk 104:230, 1968.

11. MOORHEAD, P. S.; NOWELl, P. C.; MELLMAN, W. V.; BATTIPS, D. M. \& HUNGERFORD, D. A. - Cromosome preparations of leukocytes cultured from human peripheral blood. Exp. Cell Res. 20:613-616, 1960.

12. NIEBUHR, E. - Localization of the delected segment in the "cri-du-chat" syndrome. Hum. Genet. 16:357-368, 1972.

13. PINTO Jr., W. - A sindrome do "cri-du-chat". Tese de doutoramento. Universidade Estadual de Campinas, 1972.

14. REINWEIN, H. \& WOLF, V. - "Cri-du-chat" with 5/D translocation. Lancet ii: $797,1965$.

15. SCHERES, J. M. - Human chromosome banding. Lancet i:849, 1972.

16. WABURTON, D.; Miller, D. A.; Miller, O. J.; BREG, W. R.; DE CAPOA, A. \& SHOW, M. W. - Distinction between chromosome 4 and chromosome 5 by replication pattern and lenght of long and short arms. Amer. J. hum. Genet. 19:399, 1967.

Departamento de Neuropsiquiatria e Psicologia Médica - Fraculdade de Medicina - 14100 Ribeirão Preto, SP — Brasil. 